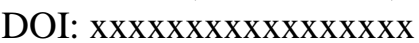

Available online at http:// jurnal.stmikroyal.ac.id/index.php/j-com

\title{
METODE EXPONENTIAL SMOOTHING PADA PERAMALAN TINGKAT KRIMINALITAS PENCURIAN SEPEDA MOTOR
}

\author{
Novianti $^{1}$, Muhammad Amin ${ }^{2 *}$, Wan Mariatul Kifti ${ }^{3}$ \\ ${ }^{1}$ Mahasiswa Prodi Sistem Informasi, STMIK Royal \\ ${ }^{2}$ Prodi Sistem Komputer, STMIK Royal \\ ${ }^{3}$ Prodi Sistem Informasi, STMIK Royal \\ *email : stmikroyal13@gmail.com
}

\begin{abstract}
This study aims to determine thecrime rate in motorbike theft cases using the programmeing langiage PHP and MySQL as a database and the application of the Exponential Smoothing method to determine the crime rate of motorcycle theft that occurs in the city of Tanjung Balai for the next period. The data used in this study is motorcycle theft report data from 2018 to 2019 wich was obtained from the Tanjung Balai Police. The benefits of this research can be used by the Tanjung Balai police to determine the extent of the motorcycle theft crime that will occur in a shorter, easier and more accurate manner so that it can take optimal prevention. With the Exponential Smoothing method the alpha value will be searched randomly to find an alpha value that was a minimum error value calculated using Means Absolute Percetage Error (MAPE). Then the prediction results that have an alphan with a minimum error are the best of recommended as a prediction result for the next period. Based on this research, the prediction results obtained from the prediction of the number of motorcycle theft cases the occurred in the city of Tanjung Balai in 2020 were 12 units with an MAPE error value of $0,153 \%$.
\end{abstract}

Keyword : Exponential Smoothing, Theft, Motorcycle, Forecasting

\begin{abstract}
Abstrak : Penelitian ini bertujuan untuk menentukan tingkat kriminalitas kasus pencurian sepeda motor dengan menggunakan bahasa pemrograman PHP dan MySQL sebagai basis data serta penerapan metode Exponential Smoothing untuk menentukan tingkat kriminalitas pencurian sepeda motor yang terjadi di kota Tanjung Balai untuk periode berikutnya. Data yang digunakan dalam penelitian ini adalah data laporan pencurian sepeda motor dari tahun 2018 sampai dengan tahun 2019 yang diperoleh dari POLRES Tanjung Balai. Manfaat dari penelitian ini dapat digunakan oleh kepolisian Tanjung Balai untuk menentukan seberapa besar tindak kriminalitas pencurian sepeda motor yang akan terjadi secara lebih singkat, mudah dan akurat sehingga dapat melakukan pencegahan yang optimal. Dengan metode Exponential Smoothing akan dicari nilai alpha secara acak sampai menemukan nilai alpha yang memiliki nilai error yang minimum yang dihitung menggunakan Means Absolute Percetage Error (MAPE). Maka hasil prediksi yang memiliki alpha dengan error minimumlah yang paling baik atau direkomendasikan sebagai hasil prediksi untuk periode selanjutnya. Berdasarkan penelitian ini diperoleh hasil prediksi peramalan jumlah kasus pencurian sepeda motor yang terjadi di kota Tanjung Balai tahun 2020 adalah 12 unit dengan nilai error MAPE sebesar 0,153\%.
\end{abstract}

Kata Kunci : Exponential Smoothing, Pencurian, Sepeda Motor, Forecasting 
Vol. 1 No. 1, Maret 2021, hlm. 15 - 20

DOI: $\operatorname{xxxxxxxxxxxxxxxxx}$

Available online at http:// jurnal.stmikroyal.ac.id/index.php/j-com

\section{PENDAHULUAN}

Kemajuan teknologi informasi saat ini begitu pesat dan berpengaruh pada proses kerja manusia yang dapat menghasilkan setiap sistem aplikasi baru. Salah satunya teknologi informasi yang dimanfaatkan oleh pihak kepolisian dalam menangani masalah tindakan kriminalitas seperti pencurian sepeda motor. Sebagaimana kita ketahui kondisi saat ini jelas terlihat tingkat kriminalitas semakin meningkat dan tidak terlepas pada daerah Kota Tanjung Balai. Pihak kepolisian Kota Tanjung Balai yang terdiri dari 6 kecamatan dan 31 kelurahan dalam menurunkan tingkat kriminalitas khususnya pencurian sepeda motor masih belum memiliki sebuah sistem peramalannya, sehingga kewaspadaan dan penanggulangan belum dilakukan secara optimal. Akibat penanggulangan yang belum optimal, kasus pencurian sepeda motor di kota Tanjung Balai terus terjadi. Dari data laporan pencurian sepeda motor pada unit Idik II SATRESKRIM POLRES Tanjung Balai dari tahun 2018 sampai 2019 tercatat ada 10 kasus pencurian sepeda motor yang dilaporkan oleh masyarakat.

Tingkat kejahatan untuk kasus pencurian sepeda motor terus meningkat dikarenakan keadaan ekonomi dan tuntutan kebutuhan hidup yang semakin tinggi. Pencurian sepeda motor dapat terjadi dimana saja seperti perumahan, sekolah, kantor, warnet, pasar, rumah/kos, bahkan di pinggiran jalan. Indikasi meningkatnya kejahatan pencurian sepeda motor tidak saja disebabkan oleh laju pertumbuhan sepeda motor semata, namun juga diperlihatkan dengan banyaknya kejahatan lainnya seperti narkoba, dan lain-lain. Pihak kepolisian dituntut untuk lebih serius dalam upaya pencegahan dan penanggulangan kejahatan pencurian sepeda motor untuk menekan laju tingginya angka kriminalitas.

Peramalan (forecasting) merupakan hal yang penting bagi setiap organisasi bisnis dan untuk setiappengambilan keputusan manajemen yang sangat signifikan [1]. Peramalan merupakan cara efektif dalam mengambil suatu keputusan karena dapat dijadikan rujukan atau pertimbangan dalam memecahkan suatu permasalah yang di hadapi. Peramalan merupakan suatu langkah proses dari sebuah aktivitas perkiraan produk yang dimasa depan dalam kurun waktu tertentu yang di buat dibuat berdasarkan data historis [2]. Peramalan biasanya diklasifikasikan berdasarkan horizon waktu masa depan yang dilingkupinya [3]. Esensi peramalan adalah perkiraan peristiwa-peristiwa di waktu yang akan datang atas dasar pola-pola di waktu yang lalu dan penggunaan kebijakan terhadap proyeksi-proyeksi dengan pola-pola di waktu yang lalu

Pada proses peramalan, agar peramalan Pada proses peramalan, agar peramalan tersebut terlaksana dengan hasil yang sesuai dengan tujuannya adalah peramalan yang mengikuti prosedur yang baik dan benar. Maka proses peramalan terdiri dari langkah langkah berikut : (1) Penentuan tujuan., (2) Penentuan tujuan., Menentukan item atau jumlah yang ingin diramalkan., (3) Menentukan jangka waktu peramalan., (4) Menentukan model peramalan., (5) Mengumpulkan data dan informasi., (6) Pengujian model peramalan., (7) Membuat peramalan., (8) Implementasi [4].

Adapun saat membangun suatu sistem dalam penentuan keputusan peramalan sangat cocok digunakan karena banyak metodenya seperti Moving Average, Exponential Smoothing dan proyeksi Trend. Dari beberapa metode yang ada, POLRES Kota Tanjung Balai dalam membangun sistem peramalan penentuan tingkat kriminalitas pencurian sepeda motor menggunakan metode Exponential Smoothing, dengan adanya 
Vol. 1 No. 1, Maret 2021, hlm. 15 - 20

DOI: $\operatorname{xxxxxxxxxxxxxxxx}$

Available online at http:// jurnal.stmikroyal.ac.id/index.php/j-com

metode tersebut dapat dipastikan keputusan yang di hasilkan akan lebih baik dan dapat di sesuikan dengan kebutuhan.

Metode Single Exponential Smoothing ini digunakan dalam memprediksi tingkat pencurian sepeda motor di Kota Tanjung Balai yang akan terjadi dimasa yang akan datang, dengan adanya metode tersebut dapat meninjau tingkat pencurian akan mengalami peningkatan atau sebaliknya. Maka masalah yang terjadi saat ini dapat diprediksi. Peramalan dengan metode Exponential Smoothing merupakan suatu metode peramalan yang memberikan bobot secara eksponensial atau bertingkat pada data-data terbarunya, sehingga data-data yang di hasilkan akan mendapatkan bobot yang lebih besar [5].

Metode SES adalah suatu prosedur yang secara terus menerus memperbaiki prediksi dengan merata-rata nilai masa lalu dari suatu data deret waktu dengan cara menurun (eksponensial). Parameter Exponential Smoothing biasanya dilambangkan dengan $\alpha($ alpha). Dalam menentukan tingkat kriminalitas pencurian sepeda motor dapat diimplementasikan dengan menggunakan bahasa pemograman PHP dan basis data MySQL serta metode peramalan yang menggunakan metode Single Exponential Smoothing.

\section{METODE}

Adapun metode yang akan digunakan dalam penelitian ini adalah kuantitatif. Riset ini mempunyai tujuan untuk membuat sistem peramalan kasus pencurian sepeda motor. Bersumber pada tujuan tersebut, hendak digunakan dengan metode Single Exponential Smoothing supaya sistem tersebut bisa dapat digunakan. Ada pula tata cara riset ini memakai pendekatan kuantitatif sebab informasi yang diperoleh dihitung menggunakan rumus Single Exponential Smoothing. Metode Single Exponential Smoothing diterapkan pada perhitungan dalam meramalkan tingkat kriminalitas pencurian sepeda motor untuk periode bulan kedepannya.

Berikut rumus untuk metode Single Exponential Smoothing :

$$
\begin{aligned}
& \mathrm{Ft}+1=\alpha \mathrm{Xt}+(1-\alpha) \mathrm{Ft} \\
& \text { dimana: } \\
& \mathrm{Ft}+1=\text { Prediksi untuk periode ke } \mathrm{t}+1 \\
& \mathrm{Xt} \quad=\text { Nilai riil/aktual periode } \mathrm{ke} \mathrm{t} \\
& \mathrm{Ft} \quad=\text { Prediksi untuk periode ke } \mathrm{t} \\
& \alpha \quad=\text { bobot yang menunjukkan konstanta penghalusan }(0<\alpha<1)
\end{aligned}
$$

\section{HASIL DAN PEMBAHASAN}

Implementasi adalah suatu tahapan yang akan di terapkan pada sistem yang di kaji berdasarkan hasil analisis dan perancangan yang telah selesai dilakukan. Tujuan yang akan dicapai pada tahapan ini berupa sistem yang dapat dioperasikan dengan baik dari hasil dan rancangan yang telah dibentuk. 
Vol. 1 No. 1, Maret 2021, hlm. 15 - 20

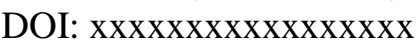

Available online at http:// jurnal.stmikroyal.ac.id/index.php/j-com

\section{Tampilan From Login}

Adapun tampilan di bawah ini adalah from login

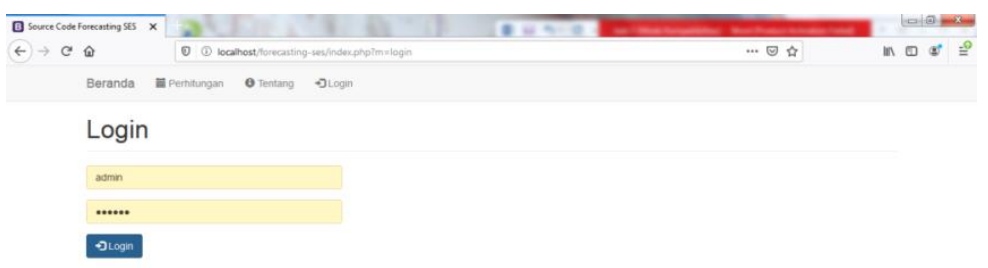

Gambar 1. Tampilan From Login

\section{Tampilan Utama Web}

Berikut ini adalah tampilan halaman utama website.

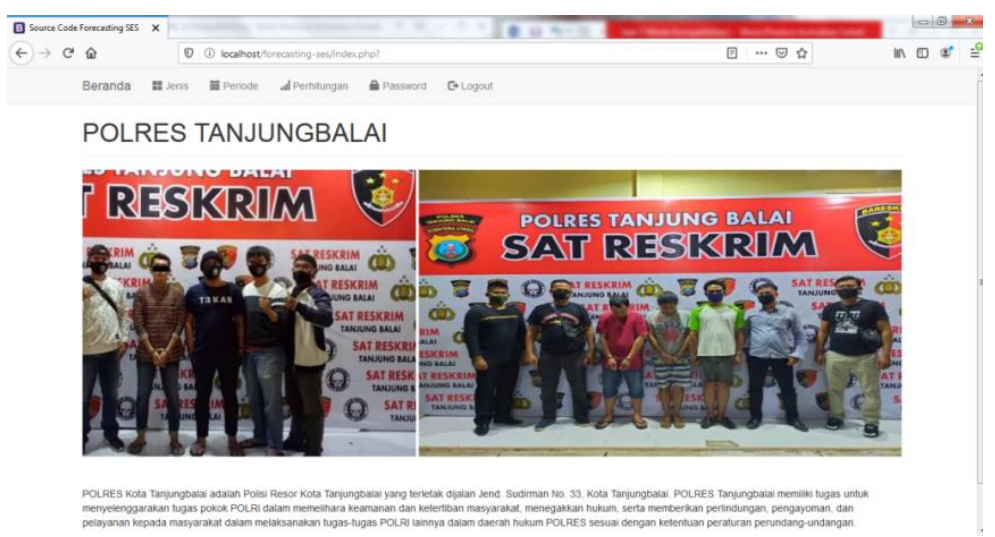

Gambar 2. Tampilan Utama Web

\section{Tampilan Jenis}

Berikut ini adalah tampilan halaman jenis sepeda motor.

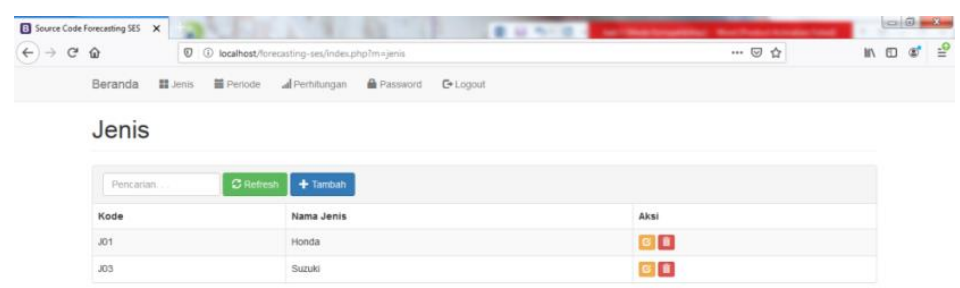

Gambar 3. Tampilan Jenis 
Vol. 1 No. 1, Maret 2021, hlm. 15 - 20

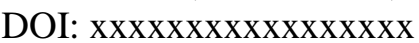

Available online at http:// jurnal.stmikroyal.ac.id/index.php/j-com

\section{Tampilan Periode}

Berikut ini adalah tampilan halaman periode kasus pencurian sepeda motor.

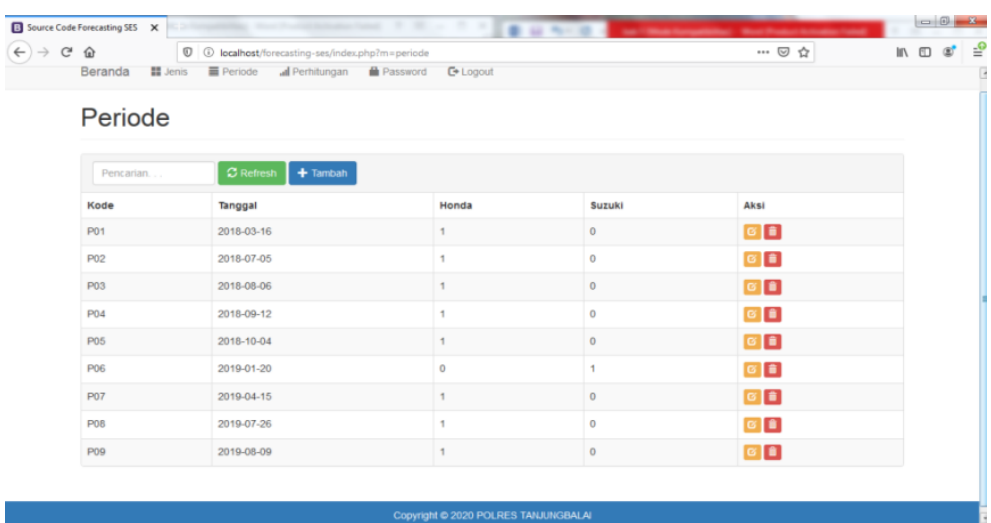

Gambar 4. Tampilan Periode

\section{Tampilan Perhitungan}

Berikut adalah tampilan halaman perhitungan peramalan kasus pencurian sepeda motor.

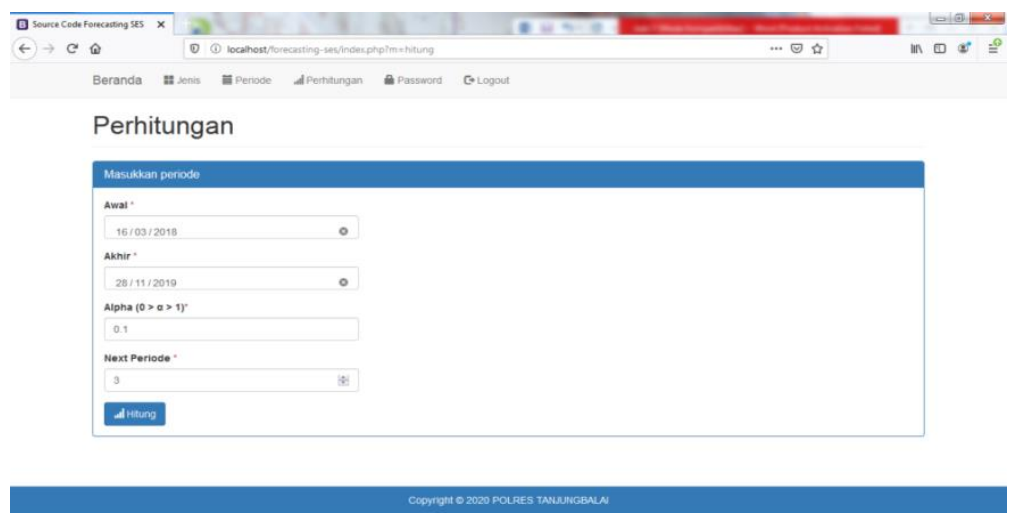

Gambar 5. Tampilan Perhitungan

\section{SIMPULAN}

Berdasarkan implementasi dan hasil pengujian pada sistem peramalan kasus pencurian sepeda motor dengan menggunakan metode Exponential Smoothing di kota Tanjung Balai di dapat kesimpulan sebagai berikut: (1) Dapat membangun sebuah aplikasi peramalan pencurian sepeda motor dengan menggunakan metode Exponential Smoothing., (2) Metode Exponential Smoothing dapat meramalkan kasus pencurian sepeda motor pada bulan berikutnya., (3) Hasil dari perhitungan yang dilakukan mendapatkan nilai MAPE dengan akurasi persentasi kesalahan terkecil 0,153\% dengan alpha 0,1. Hal ini menunjukkan bahwa peramalan terbaik untuk meramalkan kasus pencurian sepeda motor menggunakan konstanta alpha 0,1. 
Vol. 1 No. 1, Maret 2021, hlm. 15 - 20

DOI: $\operatorname{xxxxxxxxxxxxxxxxx}$

Available online at http:// jurnal.stmikroyal.ac.id/index.php/j-com

\section{DAFTAR PUSTAKA}

[1] I. D. Palandeng, F. Ekonomi, and J. Manajemen, "Analisis Ramalan Penjualan Dan Persediaan Produk Sepeda Motor Suzuki Pada Pt Sinar Galesong Mandiri Malalayang," J. EMBA J. Ris. Ekon. Manajemen, Bisnis dan Akunt., vol. 6, no. 4, pp. 2828-2837, 2018, doi: 10.35794/emba.v6i4.21067.

[2] F. Ahmad, "PENENTUAN METODE PERAMALAN PADA PRODUKSI PART NEW GRANADA BOWL ST Di PT . X Determine the actual and actual production plan is the main thing for the organization to avoid large losses in calculating the amount of production, PT . This research is to det," vol. 7, no. 1, pp. 31-39, 2020.

[3] R. Rachman, "Penerapan Metode Moving Average Dan Exponential Smoothing Pada Peramalan Produksi Industri Garment," J. Inform., vol. 5, no. 2, pp. 211220, 2018, doi: 10.31294/ji.v5i2.3309.

[4] F. M. Yuma, S. Informasi, and S. Royal, "SISTEM PERAMALAN HARGA EMAS MENGGUNAKAN METODE SINGLE EXPONENTIAL SMOOTHING," vol. 9986, no. September, 2018.

[5] W. Handoko, "Prediksi Jumlah Penerimaan Mahasiswa Baru Dengan Metode Single Exponential Smoothing (Studi Kasus: Amik Royal Kisaran)," JURTEKSI (Jurnal Teknol. dan Sist. Informasi), vol. 5, no. 2, pp. 125-132, 2019, doi: 10.33330/jurteksi.v5i2.356. 